\title{
Saffron (its active constituent, crocin) supplementation attenuates lipid peroxidation and protects against tissue injury
}

\author{
Altinoz $\mathrm{E}^{1}$, Ozmen $\mathrm{T}^{2}$, Oner $\mathrm{Z}^{3}$, Elbe $\mathrm{H}^{4}$, Erdemli $\mathrm{ME}^{5}$, Bag $\mathrm{HG}^{6}$ \\ Karabuk University, Medical Faculty, Department of Medical Biochemistry, Karabuk, Turkey. \\ eyupaltinoz@karabuk.edu.tr
}

\begin{abstract}
The aim of the current study was to investigate the outcomes in a rat model of an acute swimming exercise induced oxidative stress in brain, kidney, liver, skeletal and cardiac muscles using supplementation with crocin. Rats were divided into the eight groups; Normal Control (NC: Untreated and did not swim), Crocin Control (CC: Received crocin and did not swim), Exercise-1 (E-1: Untreated and swam), Exercise-24 (E-24: Untreated and swam), Exercise-48 (E-48: Untreated and swam), Exercise+Crocin-1 (EC-1: Received crocin and swam), Exercise+Crocin-24 (EC-24: Received crocin and swam), Exercise+Crocin-48 (EC-48: Received crocin and swam). The malondialdehyde (MDA) and xanthine oxidase (XO) enzymes levels increased after swimming in untreated and crocin treated groups, but there was a lower increase in crocin treated groups. The highest MDA levels in all tissues were observed in E-1 compared to all other groups. There were significant differences between control and exercise groups in MDA levels of tissues $(p<0.001)$. In contrast, there were significant differences between control and exercise groups in glutathione (GSH) levels of tissues.In addition, the crocin supplementation significantly increased GSH levels and decreased MDA and XO enzyme levels when compared to untreated exercise groups. Crocin can protect the tissues against exercise induced oxidative stress by enhancing antioxidant activity (Tab. 3, Fig. 1, Ref. 37). Text in PDF www.elis.sk.

KEY WORDS: crocin, GSH, MDA, oxidative stress, rats, exercise.
\end{abstract}

\section{Introduction}

Regular physical exercise can be beneficial on mental and physical development, but strenuous physical exercise leads to oxidative stress in various tissues and increase lipid peroxidation $(1,2)$. An increased metabolic rate because of exercise can elevate oxygen consumption significantly in the skeletal muscle and myocardium as well as other tissues. It has been reported that unaccustomed and strenuous exercise might exhibit an imbalance between Reactive Oxygen Species (ROS) and cellular antioxidant defense systems, resulting in the oxidative stress in the body (3, 4). ROS lead to oxidation of glutathione (GSH) and progressive cell damage by attacking all components of cell membrane(5). Lipid peroxidation is increased by exercise, accompanied with a decrease of protein thiol content (6). In addition, previous studies reported that GSH redox status decreased in both skeletal and

${ }^{1}$ Karabuk University, Medical Faculty, Department of Medical Biochemistry, Karabuk, Turkey, ${ }^{2}$ Karabuk University, Department of Physiotherapy and Rehabilitation, Karabuk, Turkey, ${ }^{3}$ Karabuk University, Medical Faculty, Department of Anatomy, Karabuk, Turkey, ${ }^{4}$ Mugla University, Medical Faculty, Department of Histology and Embryology, Mugla, Turkey, ${ }^{5}$ Inonu University, Medical Faculty, Department of Medical Biochemistry, Malatya, Turkey, and ${ }^{6}$ Inonu University, Medical Faculty, Department of Biostatistics, Malatya, Turkey

Address for correspondence: E. Altinoz, MD, Karabuk University, Medical Faculty, Department of Medical Biochemistry, 78050, Karabuk, Turkey. Phone: +90.370 .4330202$ cardiac muscles of exercised animals $(7,8)$. This condition is prevented by antioxidant supplementation (9).

The active components of saffron (Crocus sativus L.) are crocin, safranal and picrocrocin (10). Saffron is used in the traditional medicine for the treatment of several diseases such as depression, cognitive disorders, seizures and cancer (11).

Previous studies have demonstrated that saffron extract and its active ingredients, crocin and safranal, have antidepressant, antitumor, anticonvulsant, anti-inflammatory, free radical scavenging and antioxidant effects (12). In addition, it has been reported that saffron extract and its active constituents (crocin and safranal) prevent ischemia in kidney and skeletal muscle (13).

In the current study, we investigated the outcomes in a rat model of an acute swimming exercise induced oxidative stress using supplementation of animals with crocin, since elevation of the antioxidant capacity of the brain, kidney, liver, skeletal and cardiac muscles, and reducing the ROS could prevent ischemia and cell death.

\section{Material and methods}

\section{Animals experimental and protocol}

Forty-eight 4 months female Wistar rats (initial weight; 200 $\pm 20 \mathrm{~g}$ ) were kept in a room with a $12 \mathrm{~h}$ light/dark inverted cycle under standardized conditions of temperature and humidity. All animals were fed water and rat chow ad libitum. The experiments were performed in accordance with the Guide for the Care and Use 
of Laboratory Animals of Inonu University Animal Ethic Committee. At the onset of the study, rats were weighed and randomly divided into eight groups each containing 6 rats.

Group 1: Normal Control (NC: Untreated and did not swim),

Group 2: Crocin Control (CC: Received crocin and did not swim)

Group 3: Exercise-1 (E-1: Untreated and swam)

Group 4: Exercise-24 (E-24: Untreated and swam)

Group 5: Exercise-48 (E-48: Untreated and swam),

Group 6: Exercise+Crocin-1 (EC-1: Received crocin and swam) Group 7: Exercise+Crocin-24 (EC-24: Received crocin and swam) Group 8: Exercise+Crocin-48 (EC-48: Received crocin and swam).

Normal saline was administered in NC and untreated exercise groups (Exe-1, Exe-24 and Exe-48) and crocin (Sigma Chemical Co., St. Louis, MO, USA) dissolved in normal saline was administered in CC and treated exercise groups (Exe-Cro-1, Exe-Cro-24 and Exe-Cro-48) at a dose of $20 \mathrm{mg} / \mathrm{kg} /$ day (Zheng et al. 2007). All administrations were carried out at the same time and continued for 21 days with a volume of $5 \mathrm{~mL} / \mathrm{kg}$ body weight/day by gavage.

The exercise was performed in a glass pool, which was $50 \mathrm{~cm}$ in depth and width, resistant to heat and had a thermostat to keep water temperature fixed at $37^{\circ} \mathrm{C}$. Exercises were carried out only once for $30 \mathrm{~min} 24 \mathrm{~h}$ after the end of procedures (14). NC and CC were decapitated without swimming exercise. The experimental animals were made to swim in groups of two and E-1 and EC-1 were decapitated after swimming exercise. E-24 and EC-24 were decapitated $24 \mathrm{~h}$ after and E-48 and EC-48 were decapitated $48 \mathrm{~h}$ after swimming exercise under xylazine and ketamine anesthesia. Brain, kidney, liver, cardiac and gastrocnemius muscle were removed and divided into two pieces; one of the pieces was stored at $-80{ }^{\circ} \mathrm{C}$ for malondialdehyde (MDA), glutathione (GSH) and xanthine oxidase $(\mathrm{XO})$ activity measurement, and the other piece was fixed via $10 \%$ formaldehyde and used for histological evaluation.

\section{Biochemical analyses}

The brain, liver, kidney, skeletal and cardiac muscles were homogenized in ice-cold $0.1 \mathrm{M}$ Tris- $\mathrm{HCl}$ buffer $(\mathrm{pH} 7.5)$ by a homogenizer (IKA Ultra Turrax T25 basic) at 16.000 r.p.m. for 3 $\min$ at $+4{ }^{\circ} \mathrm{C}$. The homogenate was centrifuged at $10.000 \mathrm{x}$ g for 20 min at $+4{ }^{\circ} \mathrm{C}$. The obtained supernatant was used to measure MDA, GSH and XO levels.

\section{MDA analysis}

MDA is one of the end products of lipid peroxidation that reacts with thiobarbituric acid to give a specific colour absorbing at $535 \mathrm{~nm}$. MDA levels were assayed by using the method of Ohkawa (15). $0.5 \mathrm{~mL}$ supernatant was mixed with $3 \mathrm{~mL} 1 \% \mathrm{H}_{3} \mathrm{PO}_{4}$ and $1 \mathrm{~mL} 0.6 \%$ thiobarbituric acid. This mixture was heated in a boiling water bath for $45 \mathrm{~min}$. The mixture was extracted in 4 mL n-butanol. $\mathrm{n}$-butanol was used as a blank and tetramethoxypropane was used as a standard. MDA levels were expressed as $\mathrm{nmol} / \mathrm{g}$ wet tissue.

\section{GSH determination}

GSH levels were determined by Ellman method (16). Supernatant was mixed with trichloroacetic acid solution and centrifuged at $3000 \mathrm{rpm}$ at $4{ }^{\circ} \mathrm{C}$ for $20 \mathrm{~min}$. GSH reacts with 5,5-dithiobis2-nitrobenzoic acid to give a yellow species, which has a maximal absorbance at $410 \mathrm{~nm}$. Distilled water was used as a blank and GSH levels were expressed as $\mathrm{nmol} / \mathrm{g}$ wet tissue.

\section{XO determination}

$\mathrm{XO}$ activity was measured by using the method of Prajda and Weber (17). The generation of uric acid from xanthine has a maximal absorbance at $292 \mathrm{~nm}$. One unit of activity was identified as $\mu \mathrm{mol}$ of uric acid formed per min, and protein concentration was determined using biuret method. XO activity was expressed of tissues as $\mathrm{U} / \mathrm{g}$ protein.

\section{Histological evaluation}

The liver, kidney, cerebrum, cerebellum, skeletal and cardiac muscles were fixed in $10 \%$ formalin and were embedded in paraffin. Paraffin blocks were cut at $5 \mu \mathrm{m}$ and sections were stained with hematoxylin-eosin (H-E). All sections were examined using a Leica DFC280 light microscope and a Leica Q Win and Image

Tab. 1. The levels of MDA in brain, kidney, liver, cardiac and skeletal muscle.

\begin{tabular}{|c|c|c|c|c|c|c|c|c|}
\hline & Time & Treatment & $\mathrm{n}$ & $\begin{array}{c}\text { Brain } \\
\text { Mean } \pm \text { SD }\end{array}$ & $\begin{array}{c}\text { Kidney } \\
\text { Mean } \pm \text { SD }\end{array}$ & $\begin{array}{c}\text { Myocard } \\
\text { Mean } \pm \text { SD }\end{array}$ & $\begin{array}{c}\text { Liver } \\
\text { Mean } \pm \text { SD }\end{array}$ & $\begin{array}{c}\text { Skeletal Muscle } \\
\text { Mean } \pm \text { SD }\end{array}$ \\
\hline \multirow{2}{*}{ Control } & \multirow{2}{*}{$0 \mathrm{~h}$} & Untreated & 6 & $911.17 \pm 43.23$ & $997.00 \pm 59.62$ & $628.67 \pm 80.90$ & $564.50 \pm 119.37$ & $501.33 \pm 74.04$ \\
\hline & & Crocin & 6 & $847.00 \pm 70.99$ & $865.00 \pm 132.21$ & $599.00 \pm 128.65$ & $298.67 \pm 39.70$ & $428.83 \pm 64.82$ \\
\hline \multirow{6}{*}{ Exercise } & \multirow{2}{*}{$0 \mathrm{~h}$} & Untreated & 6 & $1563.50 \pm 72.89$ & $1488.50 \pm 168.46$ & $1260.17 \pm 186.99$ & $954.67 \pm 33.55$ & $1037.33 \pm 1122.50$ \\
\hline & & Crocin & 6 & $996.17 \pm 40.68$ & $1292.00 \pm 84.16$ & $822.00 \pm 22.91$ & $860.00 \pm 88.66$ & $738.33 \pm 35.77$ \\
\hline & \multirow{2}{*}{$24 \mathrm{~h}$} & Untreated & 6 & $1175.33 \pm 116.55$ & $1366.50 \pm 99.23$ & $1142.50 \pm 125.99$ & $938.17 \pm 44.91$ & $823.00 \pm 26.41$ \\
\hline & & Crocin & 6 & $921.83 \pm 132.15$ & $1111.17 \pm 77.69$ & $803.50 \pm 15.78$ & $823.50 \pm 112.86$ & $709.00 \pm 34.61$ \\
\hline & \multirow{2}{*}{$48 \mathrm{~h}$} & Untreated & 6 & $1006.83 \pm 111.12$ & $1051.33 \pm 62.91$ & $822.83 \pm 37.09$ & $935.17 \pm 113.40$ & $796.17 \pm 32.36$ \\
\hline & & Crocin & 6 & $914.00 \pm 68.81$ & $935.67 \pm 48.83$ & $629.33 \pm 89.74$ & $746.00 \pm 124.59$ & $621.50 \pm 52.21$ \\
\hline \multirow{5}{*}{$\begin{array}{l}\text { Source of } \\
\text { Variation }\end{array}$} & \multicolumn{3}{|c|}{ Group } & $\mathrm{p}<0.001$ & $\mathrm{p}<0.001$ & $\mathrm{p}<0.001$ & $\mathbf{p}<0.001$ & $p=0.013$ \\
\hline & \multicolumn{3}{|l|}{ Time } & $\mathrm{p}<0.001$ & $\mathrm{p}<0.001$ & $\mathrm{p}<0.001$ & $\mathrm{p}=0.215$ & $\mathrm{p}=0.539$ \\
\hline & \multicolumn{3}{|c|}{ Treatment } & $\mathrm{p}<0.001$ & $\mathrm{p}<0.001$ & $\mathrm{p}<0.001$ & $\mathrm{p}<0.001$ & $\mathrm{p}=0.293$ \\
\hline & \multicolumn{3}{|c|}{ Group*Treatment } & $\mathrm{p}<0.001$ & $\mathrm{p}=0.431$ & $\mathrm{p}<0.001$ & $p=0.028$ & $\mathrm{p}=0.491$ \\
\hline & \multicolumn{3}{|c|}{ Time* Treatment } & $p<0.001$ & $\mathrm{p}=0.236$ & $p=0.020$ & $\mathrm{p}=0.424$ & $\mathrm{p}=0.847$ \\
\hline
\end{tabular}

Data are expressed as the mean \pm SD. The groups with different superscripts represent the statistical significance. $p<0.05$ was considered as significant. 
Analysis system (Leica Micros Imaging Solutions Ltd., Cambridge, UK).

\section{Statistical analysis}

Statistical analysis was carried out using the SPSS for Windows version 13.0 (SPSS Inc., Chicago, III., USA) statistical program. The data were expressed as the mean value and standard deviation (mean $\pm \mathrm{SD}$ ). Under consideration of the three independent factors (group, treatment, time), the comparisons were made by three-way analysis of variance. After anova, pairwise comparisons were made by Bonferroni adjusted multiple comparison method. $\mathrm{p}<0.05$ was regarded as significant.

\section{Results}

\section{Biochemical findings}

Table 1 presents the levels of MDA in the brain, kidney, liver, cardiac and skeletal muscles. The highest MDA levels in all tissues were observed in E-1 group compared to all other groups. The MDA levels decreased in all tissues at $48 \mathrm{~h}$ compared to 24 $\mathrm{h}$ and $0 \mathrm{~h}$ when treatment and group effects were not accounted.
The crocin treatment decreased the MDA levels in both control and exercise groups when treatment and group effects were accounted. In addition, the MDA levels in the crocin treated exercise groups were lower than untreated exercise groups when time and group effects were not accounted.

Table 2 presents the levels of $\mathrm{XO}$ in brain, kidney, liver, cardiac and skeletal muscles. XO levels in control groups were lower than exercise groups when time and treatment were not accounted. Also, crocin treatment caused a decrease in XO levels when time and group effects were not accounted.

Table 3 presents the levels of GSH in brain, kidney, liver, cardiac and skeletal muscles. The GSH levels in crocin treated groups were higher than in untreated groups when time and group effects were not accounted. Swimming exercise caused a decrease GSH levels in both crocin treated and untreated exercise groups when time and group effects were not accounted. However, GSH levels in crocin treated exercise groups were higher than in untreated exercise groups.

\section{Histological findings}

In the control group in all tissues, histological appearance was normal structure and the crocin groups were similar to the control.

Tab. 2. The levels of XO in brain, kidney, liver, cardiac and skeletal muscle.

\begin{tabular}{|c|c|c|c|c|c|c|c|c|}
\hline Group & Time & Treatment & $\mathrm{n}$ & $\begin{array}{c}\text { Brain } \\
\text { Mean } \pm \text { SD }\end{array}$ & $\begin{array}{c}\text { Kidney } \\
\text { Mean } \pm \text { SD }\end{array}$ & $\begin{array}{c}\text { Myocard } \\
\text { Mean } \pm \text { SD }\end{array}$ & $\begin{array}{c}\text { Liver } \\
\text { Mean } \pm \text { SD }\end{array}$ & $\begin{array}{c}\text { Skeletal Muscle } \\
\text { Mean } \pm \text { SD }\end{array}$ \\
\hline \multirow{2}{*}{ Control } & \multirow{2}{*}{ Oh } & Untreated & 6 & $0.95 \pm 0.13$ & $0.84 \pm 0.14$ & $0.46 \pm 0.26$ & $0.24 \pm 0.08$ & $0.17 \pm 0.06$ \\
\hline & & Crocin & 6 & $0.87 \pm 0.51$ & $0.95 \pm 0.36$ & $0.32 \pm 0.07$ & $0.32 \pm 0.19$ & $0.27 \pm 0.19$ \\
\hline \multirow{6}{*}{ Exercise } & \multirow{2}{*}{ Oh } & Untreated & 6 & $2.84 \pm 2.10$ & $3.53 \pm 1.41$ & $3.91 \pm 2.26$ & $3.29 \pm 1.41$ & $4.56 \pm 0.92$ \\
\hline & & Crocin & 6 & $1.16 \pm 0.49$ & $2.39 \pm 1.40$ & $2.25 \pm 1.43$ & $1.50 \pm 1.54$ & $2.34 \pm 1.12$ \\
\hline & \multirow{2}{*}{$24 \mathrm{~h}$} & Untreated & 6 & $3.45 \pm 1.68$ & $2.96 \pm 1.97$ & $3.70 \pm 2.26$ & $2.99 \pm 2.44$ & $4.38 \pm 3.69$ \\
\hline & & Crocin & 6 & $1.14 \pm 0.51$ & $2.32 \pm 0.41$ & $3.06 \pm 1.64$ & $1.33 \pm 0.45$ & $2.32 \pm 1.06$ \\
\hline & \multirow{2}{*}{$48 \mathrm{~h}$} & Untreated & 6 & $1.99 \pm 1.41$ & $2.86 \pm 2.71$ & $3.39 \pm 0.97$ & $2.87 \pm 0.73$ & $2.97 \pm 1.58$ \\
\hline & & Crocin & 6 & $0.91 \pm 0.47$ & $2.20 \pm 1.85$ & $3.22 \pm 2.13248$ & $1.02 \pm 1.46$ & $2.06 \pm 1.09$ \\
\hline \multirow{5}{*}{$\begin{array}{l}\text { Source of } \\
\text { Variation }\end{array}$} & \multicolumn{3}{|c|}{ Group } & $p=0.023$ & $\mathrm{p}=0.002$ & $\mathrm{p}<0.001$ & $\mathrm{p}<0.001$ & $\mathrm{p}<0.001$ \\
\hline & \multicolumn{3}{|c|}{ Time } & $\mathrm{p}=0.195$ & $\mathrm{p}=0.776$ & $\mathrm{p}=0.894$ & $\mathrm{p}=0.689$ & $\mathrm{p}=0.304$ \\
\hline & \multicolumn{3}{|c|}{ Treatment } & $p=0.003$ & $\mathrm{p}=0.387$ & $\mathrm{p}=0.400$ & $p=0.009$ & $\mathrm{p}=0.056$ \\
\hline & \multicolumn{3}{|c|}{ Group*Treatment } & $\mathrm{p}=0.090$ & $\mathrm{p}=0.325$ & $\mathrm{p}=0.251$ & $\mathrm{p}=0.080$ & $\mathrm{p}=0.084$ \\
\hline & \multicolumn{3}{|c|}{ Time* Treatment } & $\mathrm{p}=0.418$ & $\mathrm{p}=0.903$ & $\mathrm{p}=0.511$ & $\mathrm{p}=0.983$ & $\mathrm{p}=0.558$ \\
\hline
\end{tabular}

Data are expressed as the mean \pm SD. The groups with different superscripts represent the statistical significance. $p<0.05$ was considered as significant.

Tab. 3. The levels of GSH in brain, kidney, liver, cardiac and skeletal muscle.

\begin{tabular}{|c|c|c|c|c|c|c|c|c|}
\hline Group & Time & Treatment & $\mathrm{n}$ & $\begin{array}{c}\text { Brain } \\
\text { Mean } \pm \text { SD }\end{array}$ & $\begin{array}{c}\text { Kidney } \\
\text { Mean } \pm \text { SD }\end{array}$ & $\begin{array}{l}\text { Myocard } \\
\text { Mean } \pm \text { SD }\end{array}$ & $\begin{array}{c}\text { Liver } \\
\text { Mean } \pm \text { SD }\end{array}$ & $\begin{array}{c}\text { Skeletal Muscle } \\
\text { Mean } \pm \text { SD }\end{array}$ \\
\hline \multirow{2}{*}{ Control } & \multirow{2}{*}{$0 \mathrm{~h}$} & Untreated & 6 & $795.83 \pm 103.33$ & $229.67 \pm 30.19$ & $362.17 \pm 90.19$ & $1563.00 \pm 361.74$ & $451.83 \pm 35.54$ \\
\hline & & Crocin & 6 & $862.17 \pm 177.19$ & $446.67 \pm 349.45$ & $477.67 \pm 46.81$ & $1947.83 \pm 117.46$ & $582.83 \pm 92.89$ \\
\hline \multirow{6}{*}{ Exercise } & \multirow{2}{*}{ Oh } & Untreated & 6 & $412.33 \pm 58.87$ & $239.33 \pm 23.62$ & $272.50 \pm 157.49$ & $1259.50 \pm 365.19$ & $424.17 \pm 51.78$ \\
\hline & & Crocin & 6 & $683.50 \pm 89.13$ & $307.67 \pm 30.10$ & $346.17 \pm 106.80$ & $1563.83 \pm 210.59$ & $506.33 \pm 83,99$ \\
\hline & \multirow{2}{*}{$24 \mathrm{~h}$} & Untreated & 6 & $504.17 \pm 117.24$ & $277.67 \pm 56.46$ & $295.83 \pm 44.92$ & $1344.00 \pm 329.38$ & $426.33 \pm 37.70$ \\
\hline & & Crocin & 6 & $759.67 \pm 39.04$ & $321.50 \pm 41.16$ & $366.33 \pm 74.75$ & $1924.17 \pm 692.37$ & $560.83 \pm 228.60$ \\
\hline & \multirow{2}{*}{$48 \mathrm{~h}$} & Untreated & 6 & $569.33 \pm 38.37$ & $290.50 \pm 68.70$ & $375.17 \pm 102.36$ & $1383.67 \pm 403.27$ & $452.00 \pm 83.71$ \\
\hline & & Crocin & 6 & $762.83 \pm 44.34$ & $336.50 \pm 44.56$ & $404.83 \pm 74.16$ & $1957.17 \pm 604.13$ & $573.67 \pm 111.04$ \\
\hline \multirow{5}{*}{$\begin{array}{l}\text { Source of } \\
\text { Variation }\end{array}$} & \multicolumn{3}{|c|}{ Group } & $\mathrm{p}<\mathbf{0 . 0 0 1}$ & $\mathrm{p}=0.232$ & $\mathrm{p}=0.006$ & $\mathrm{p}=0.054$ & $\mathrm{p}=0.243$ \\
\hline & \multicolumn{3}{|l|}{ Time } & $\mathrm{p}=0.066$ & $\mathrm{p}=0.749$ & $\mathrm{p}=0.105$ & $\mathrm{p}=0.281$ & $\mathrm{p}=0.557$ \\
\hline & \multicolumn{3}{|c|}{ Treatment } & $\mathrm{p}<0.001$ & $\mathrm{p}=\mathbf{0 . 0 1 0}$ & $p=0.013$ & $p=0.001$ & $p=0.001$ \\
\hline & \multicolumn{3}{|c|}{ Group*Treatment } & $p=0.012$ & $\mathrm{p}=0.170$ & $\mathrm{p}=0.587$ & $\mathrm{p}=0.817$ & $\mathrm{p}=0.581$ \\
\hline & \multicolumn{3}{|c|}{ Time* Treatment } & $\mathrm{p}=0.575$ & $\mathrm{p}=0.968$ & $\mathrm{p}=0.815$ & $\mathrm{p}=0.664$ & $\mathrm{p}=0.825$ \\
\hline
\end{tabular}

Data are expressed as the mean $\pm \mathrm{SD}$. The groups with different superscripts represents the statistical significance. $\mathrm{p}<0.05$ was considered as significant. 


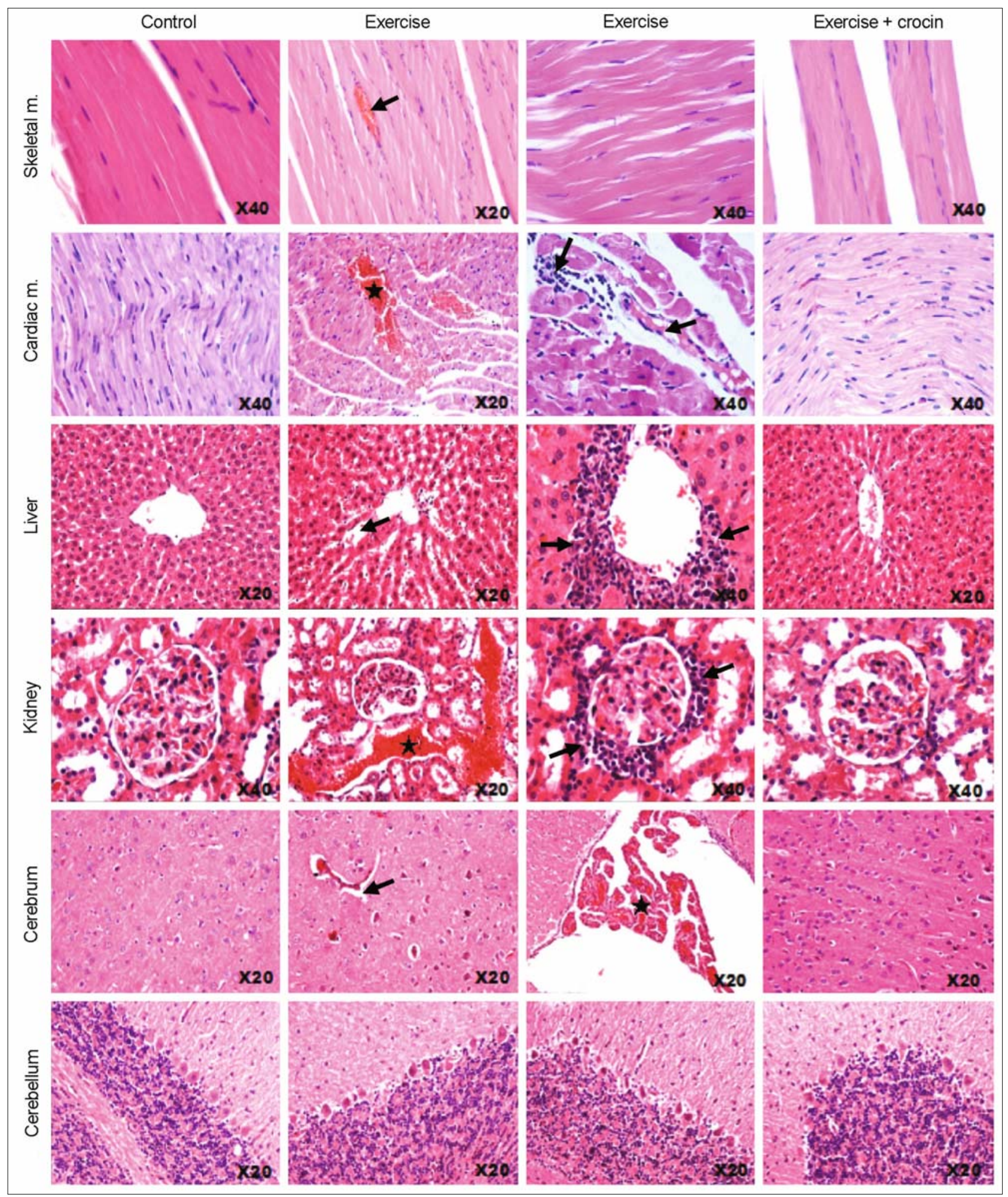

Fig. 1. Photomicrographs of all tissues. Histological appearance was normal in the control and crocin groups. In the exercise group, histopathological changes were detected. In skeletal muscle; haemorrhage (arrow), inflammatory cells and breakdown of myofibrils, in cardiac muscle; haemorrhagic area (star), inflammatory cells (thick arrow) and vacuolization (thin arrow), in liver; sinusoidal dilatation (arrow), periportal inflammation (arrows) and congestion, in kidney; haemorrhage (star), inflammation (arrows), tubular cast and degenerated glomeruli, in cerebrum; perivascular edema (arrow), congested choroid plexus (star), in cerebellum; degenerated Purkinje cell and loss of Purkinje cell were observed. In the exercise + crocin groups, histopathological changes reduced. 
In the exercise groups, histopathological changes were detected. In the skeletal muscle, inflammation, breakdown of myofibrils and hemorrhagic areas were detected. In the cardiac muscle, inflammation, haemorrhage and vacuolization were observed. In liver, moderate histopathological changes were detected such as: congestion, periportal inflammation and sinusoidal dilatation. In kidneys, severe glomerular and tubular changes were detected such as: haemorrhage, inflammation, tubular cast and degenerated glomeruli. In cerebrum, perivascular and perineuronaledema, congested choroid plexus were observed. In cerebellum degenerated purkinje cell and loss of purkinje cell were detected. On the other hand, in the exercise + crocin groups in all tissues, these histopathological changes were reduced (Fig. 1).

\section{Discussion}

The present study was undertaken to evaluate the effects of the crocin treatment by gavage on parameters associated with oxidative stress in the several tissues of rats submitted to swimming exercise stress. In our study, the highest MDA levels in all tissues were determined in the E-1 group compared to all other groups. MDA levels decreased gradually in all tissues of E-48 compared to E-1 and E-24 without the crocin treatment. However, the MDA levels in the crocin treatment groups were lower when compared to the untreated exercise groups. Our main finding, crocin ameliorated the responses induced by exhaustive swimming exercise associated with oxidative stress, since it decreased the MDA and the XO levels in all tissues. In addition, the crocin treatment increased GSH levels in all tissues.

It is reported that a strenuous exercise can lead to oxidative stress by increasing the formation of ROS (18). According to our findings, the MDA, an indirect product of the oxidative degradation of lipids in cell components, and the increase in MDA levels, might be indicative of oxidative stress, was increased in all tissues of rats after swimming exercise. The ratio of lipid peroxidation is related with the intensity and mode of exercise. For example, short-term exhaustive exercise can accelerate lipid peroxidation in skeletal muscle $(19,20)$, whereas long-term aerobic exercise can decrease lipid peroxidation and prevent tissue injuries (21). These reports demonstrated that an intense physical exercise raises oxidative damage both in humans and experimental animals $(19,20)$. In the current study, the highest MDA concentrations in all tissues were observed in the swimming exercise group (Exe-1), and the MDA values decreased gradually at $24 \mathrm{~h}$ (E-24) and $48 \mathrm{~h}$ (E-48) after swimming exercise. We cope with lipid peroxidation induced by an acute swimming exercise in several tissues of rats. Our results are in line with the results of the researchers, who consider that intense and/or acute exercise accelerates ROS production. Indeed, an acute exercise led to increased lipid peroxidation, especially in the brain (14), kidney (22) and skeletal muscle (19). Also, previous studies have demonstrated that exercise leads to oxidative stress and increases oxidative damage biomarkers, such as MDA in rat skeletal muscle (23) and kidney (24). The results of the studies are important findings supporting our results, as the elevated levels of MDA determined in the brain, kidney, liver, skeletal and cardiac muscles of the swimming exercise group (E1). We also found that the MDA levels decreased gradually at 24 $\mathrm{h}$ and $48 \mathrm{~h}$ without any treatment. Also, the crocin treatment decreased the MDA levels significantly compared to the untreated exercise groups.

Hellsten et al (25) found that the XO is an important source of ROS during exercise owing to increased purine oxidation. Other main source of the ROS is mitochondria. They play an important role to provide the cell with metabolic energy in the form of ATP. In normal conditions, the oxygen is used as an electron acceptor and reduced to produce water, however, in about $0.1-2 \%$ of electrons passing through during the mitochondrial electron transport chain, oxygen is reduced incompletely to generate ROS. Therefore, ROS can be produced normally as a by product of the respiration process. If the production of the ROS is overwhelming, they attach the macromolecular components of the cell and cell membrane leading to structural and functional alterations of these molecules. Previous studies have demonstrated that the XO can produce superoxide generation in skeletal muscle (26). We also found that the XO levels were increased after swimming especially at $24 \mathrm{~h}$ in all tissues. It has been reported that allopurinol prevented tissue damage related to an exhaustive exercise in animals (27) and humans (20). Allopurinol is used world-wide in clinical practice, but it might act as antioxidant (28). In the current study, the XO levels in all tissues of the crocin treated groups were significantly lower than in the untreated exercise groups.

In the current study, the GSH levels were improved by crocin in the treated exercise groups compared to the untreated exercise groups. Normally, the level of oxidative stress is arranged by enzymatic and non-enzymatic antioxidant systems. Reduced GSH is presents abundantly in cells and plays an important role in the antioxidant defense system of the cells as the part of nonenzymatic antioxidant. GSH can destroy free radicals, reduce hydrogen peroxide and is converted to its oxidized form, glutathionedisulfide (GSSG). Reduced GSH comprises more than $90 \%$ of the total GSH pool and less than $10 \%$ of the total GSH present in GSSG form in healthy cells. The elevated GSSG/GSH ratio is a good indicator of oxidative stress (29). Depletion of GSH in cells relates to the mode, time, intensity of the exercise, and training conditions and is in line with a decrease in plasma concentration of this substance (30). An exhaustive exercise leads to an increase of the ROS production and decrease of the GSH content in tissues (31). Consistent with these findings, this study showed that the levels of GSH decreased significantly after swimming exercise, but increased gradually at $24 \mathrm{~h}$ and $48 \mathrm{~h}$. One important finding of this study is that decreased GSH content was not observed in the crocin treated exercise group in liver tissues of rats, which presumably expresses an ameliorated antioxidant status in liver. However, our results showed that the GSH content decreased little in other tissues of crocin treated exercise groups. The GSH consumption in all tissues was significantly higher after a swimming exercise. Following the swimming exercise at $24 \mathrm{~h}$ and 48 $\mathrm{h}$, GSH content of tissues increased gradually. In addition, crocin treatment was observed in the antioxidant defense, and this could 
spare GSH consumption in higher oxidative stress conditions, preserving its concentrations.

It has been reported that saffron supplementation during an eccentric activity decreased enzymatic activity of creatine kinase (CK), however did not change the lactate dehydrogenase (LDH) activity (32). Elevated levels of CK and LDH are indicators of inflammation and pathological consequences of DOMS. Similarly, saffron exhibited a protection of CK and LDH elevation after an eccentric exercise (33). As the raise of antioxidant capacity after crocin supplementation is concerned, the findings of the present study are supported by previous studies. Saffron can prevent the oxidative stress due to its chemical compounds, because saffron and crocin, crocetin, and safranal compounds have antioxidant properties and can destroy free radicals.

Another study found that crocetin prevented aflatoxin induced hepatic injury due to its antioxidant effect in rats (34). Also, saffron, crocin and crocetin might protect from oxidative damage of kidney in rats (35). In addition, our previous studies demonstrated that crocin could inhibit oxidative injuries of the brain and the kidney tissues in the diabetic rats $(36,37)$.

\section{Conclusions}

The results of the present study demonstrated that an acute swimming exercise caused a generation of free radicals in several tissues but crocin treatment prevents the free radical formation by improving the antioxidant activity. As a conclusion, the crocin treatment at a physiological dose might contribute to exercise performance by preventing the free radical production and protecting tissues against apoptosis after an exhaustive exercise challenge.

\section{References}

1. Teixeira AM, Reckziegel P, Müller L, Pereira RP, Roos DH, Rocha JB et al. Intense exercise potentiates oxidative stress in striatum of reserpine-treated animals. Pharmacol Biochem Behav 2009; 92: 231-235.

2. Benderitter M, Hadj-Saad F, Lhuissier M, Maupoil V, Guilland JC, Rochette L. Effects of exhaustive exercise and vitamin B 6 deficiency on free radical oxidative process in male trained rats. Free Rad Biol Med 1996; 21: 541-549.

3. Ji LL. Exercise and oxidative stress: role of the cellular antioxidant systems. Exerc Sport Sci Rev 1995; 23: 135-166.

4. Sen CK. Oxidants and antioxidants in exercise. J Appl Physiol 1995; 79: 675-686.

5. Jackson M. Muscle damage during exercise: possible role of free radicals and protective effect of vitamin E. Proc Nutrit Soc 1987; 46: 77-80.

6. Ji LL, Stratman FW, Lardy HA. Enzymatic down regulation with exercise in rat skeletal muscle. Arch Biochem Biophys 1988; 263: 137-149.

7. Chandwaney R, Leichtweis S, Leeuwenburgh C, Ji LL. Oxidative stress and mitochondrial function in skeletal muscle: effects of aging and exercise training. Age 1998; 21: 109-117.

8. Leichtweis S, Leeuwenburgh C, Parmelee D, Fiebig R, Ji L. Rigorous swim training impairs mitochondrial function in post-ischaemic rat heart. Acta Physiol Scand 1997; 160: 139-148.
9. Sastre J, Asensi M, Gasco E, Pallardo FV, Ferrero J, Furukawa T et al. Exhaustive physical exercise causes oxidation of glutathione status in blood: prevention by antioxidant administration. Amer J Physiol 1992; 263: R992-R995.

10. Tarantilis PA, Tsoupras G, Polissiou M. Determination of saffron (Crocus sativus L.) components in crude plant extract using high-performance liquid chromatography-UV-visible photodiode-array detection-mass spectrometry. J Chromatogr A 1995; 699: 107-118.

11. Bathaie SZ, Mousavi SZ. New applications and mechanisms of action of saffron and its important ingredients. Crit Rev Food Sci Nutrit 2010; 50: 761-786.

12. Abdullaev F. Biological effects of saffron. BioFactors (Oxford, England) 1993 ; 4: 83-86.

13. Hosseinzadeh H, Modaghegh MH, Saffari Z. Crocus sativus L.(Saffron) extract and its active constituents (crocin and safranal) on ischemia-reperfusion in rat skeletal muscle. Evid Complement Alternat Med 2009; 6: 343-350.

14. Akil M, Bicer M, Menevse E, Baltaci A, Mogulkoc R. Selenium supplementation prevents lipid peroxidation caused by arduous exercise in rat brain tissue. Bratisl Lek Listy 2010; 112: 314-317.

15. Ohkawa H, Ohishi N, Yagi K. Assay for lipid peroxides in animal tissues by thiobarbituric acid reaction. Anal Biochem 1979; 95: 351-358.

16. Ellman GL. Tissue sulfhydryl groups. Arch Biochem Biophys 1959; 82: $70-77$.

17. Prajda N, Weber G. Malignant transformation-linked imbalance: decreased xanthine oxidase activity in hepatomas. Febs Lett 1975; 59: $245-249$.

18. Sen CK. Antioxidant and redox regulation of cellular signaling: introduction. Med Sci Sport Exercis 2001; 33: 368-370.

19. Bachur JA, Garcia SB, Vannucchi H, Jordao AA, Chiarello PG, Zucoloto S. Anti-oxidative systems in rat skeletal muscle after acute physical exercise. Appl Physiol Nutrit Metab 2007; 32: 190-196.

20. Gómez-Cabrera M-C, Pallardó FV, Sastre J, Viña J, García-delMoral L. Allopurinol and markers of muscle damage among participants in the Tour de France. JAMA 2003; 289: 2503-2504.

21. Kihlstrom M. Protection effect of endurance training against reoxygenation-induced injuries in rat heart. J Appl Physiol 1990; 68: 1672-1678.

22. Bucioli SA, de Abreu LC, Valenti VE, Leone C, Vannucchi H. Effects of vitamin E supplementation on renal non-enzymatic antioxidants in young rats submitted to exhaustive exercise stress. BMC Complement Altern Med 2011; 11: 133.

23. Oh-Ishi S, Kizaki T, Ookawara T, Toshinai K, Haga S, Karasawa F et al. The effect of exhaustive exercise on the antioxidant enzyme system in skeletal muscle from calcium-deficient rats. Pflügers Arch 1998; 435: 767-774.

24. Ji LL. Antioxidants and oxidative stress in exercise. Exp Biol Med 1999; 222: 283-292.

25. Hellsten Y, Ahlborg G, Jensen-Urstad M, Sjödin B. Indication of in vivo xanthine oxidase activity in human skeletal muscle during exercise. Acta Physiol Scand 1988; 134: 159-160.

26. Gomez-Cabrera MC, Close GL, Kayani A, McArdle A, Vina J, Jackson MJ. Effect of xanthine oxidase-generated extracellular superoxide on skeletal muscle force generation. Amer J Physiol 2010; 298 : R2-R8. 
27. Viña J, Gimeno A, Sastre J, Desco C, Asensi M, Pallardó FV et al. Mechanism of free radical production in exhaustive exercise in humans and rats; role of xanthine oxidase and protection by allopurinol. IUBMB Life 2000; 49: 539-544.

28. Moorhouse PC, Grootveld M, Halliwell B, Quinlan JG, Gutteridge JM. Allopurinol and oxypurinol are hydroxyl radical scavengers. FEBS Lett 1987; 213: 23-28.

29. Halprin KM, Ohkawara A. The Measurement of Glutathione in Human Epidermis Using Glutathione Reductase 1. J Invest Dermatol 1967; 48: 149-152.

30. Kretzschmar M, Müller D. Aging, training and exercise. Sports Med 1993; 15: 196-209.

31. Minato K-i, Miyake Y, Fukumoto S, Yamamoto K, Kato Y, Shimomura $Y$ et al. Lemon flavonoid, eriocitrin, suppresses exercise-induced oxidative damage in rat liver. Life Sci 2003; 72: 1609-1616.

32. Musaie M, Azarbayjani MA, Peeri M. The responses of creatine kinase and lactate dehydrogenase to acute eccentric activity after saffron supplementation in healthy man. Internat J Biosci 2013; 3: 319-324.
33. Meamarbashi A, Rajabi A. Preventive Effects of 10-Day Supplementation With Saffron and Indomethacin on the Delayed-Onset Muscle Soreness. Clin J Sport Med 2014.

34. Wang CJ, Shiow SJ, Lin JK. Effects of crocetin on the hepatotoxicity and hepatic DNA binding of aflatoxin B1 in rats. Carcinogenesis 1991; 12: 459-462.

35. Hosseinzadeh H, Talebzadeh F. Anticonvulsant evaluation of safranal and crocin from Crocus sativus in mice. Fitoterapia 2005; 76: 722-724.

36. Altinoz E, Oner Z, Elbe H, Vardi N. Neuro-protective effects of crocin on brain and cerebellum tissues in diabetic rats. Afr J Trad Complement Altern Med 2014; 11: 33-39.

37. Altinoz E, Oner Z, Elbe H, Turkoz Y, Cigremis Y. Protective effect of saffron (its active constituent, crocin) on oxidative stress and hepatic injury in streptozotocin induced diabetic rats. Gene Ther Mol Biol 2014; 16: $160-171$.

Received November 6, 2015. Accepted November 20, 2015. 